\title{
Um currículo para uma formação, a que será que se destina?
}

Margareth Sacramento Rotondo ${ }^{1}$

Universidade Federal de Juiz de Fora - UFJF

Giovani Cammarota ${ }^{2}$

Universidade Federal de Juiz de Fora - UFJF

Sônia Maria Clareto ${ }^{3}$

Universidade Federal de Juiz de Fora - UFJF

\begin{abstract}
RESUMO
O artigo apresenta uma escrita em aforismos problematizando currículo e formação de professoras e de professores e, em composição, arrasta educação e educação matemática e escola e salas de aulas e saberes e matemática e e e... Um currículo para uma formação se produz como experimento e, com ele, um modelo teleológico é assumido como meta a ser a atingida, então, experimentação certa. Um currículo para uma formação que carrega modos canônicos, hegemônicos, universais, aliados à Moral, à Verdade, ao Bem e ao Belo, no empreendimento do ideal e no controle do existir. Uma professora e um professor num porto seguro apostando em uma verdade curricular que tem no outro um incapaz infantilizado, desprovido de razão, então aciona o seu dever de conduzi-lo à boa forma. Uma pedagogização do currículo. E, com tudo isso, em experimentação: um currículo no que acontece, uma formação enquanto processo, involução. E, com o que há institucionalizado, demarcado e postulado, torções. E, em composição: currículo e formação docente no que acontece. Processos formativos em experimentação resistem a modelos e metas afectados pelos signos que se apresentam com as forças que se instauram e disputam em favor de outros modos de existir e conhecer. Certas experimentações no que acontece, currículo no que acontece: currículo
\end{abstract}

Submetido em: 08/01/2022

Aceito em: 14/02/2022

Publicado em: 08/03/2022

\begin{abstract}
${ }^{1}$ Doutora em Educação Matemática pela Universidade Estadual Paulista "Júlio de Mesquita Filho" (UNESP), campus Rio Claro. Professor Associada na Universidade Federal de Juiz de Fora (UFJF), Juiz de Fora, Minas Gerais, Brasil. Endereço para correspondência: Campus Universitário, Rua José Lourenço Kelmer, São Pedro, Juiz de Fora, MG, Brasil, CEP: 36036-900. ORCID: https://orcid.org/0000-0001-6102-4901. E-mail: sacramento.rotondo@ufjf.br

2Doutor em Educação pela Universidade Estadual Paulista "Júlio de Mesquita Filho" (UNESP), campus Rio Claro. Professor Adjunto na Universidade Federal de Juiz de Fora (UFJF), Juiz de Fora, Minas Gerais, Brasil. Endereço para correspondência: Campus Universitário, Rua José Lourenço Kelmer, São Pedro, Juiz de Fora, MG, Brasil, CEP: 36036900. ORCID: https://orcid.org/0000-0002-7816-0376. E-mail: giovani.cammarota@educacao.ufjf.br

${ }^{3}$ Doutora em Educação Matemática pela Universidade Estadual Paulista "Júlio de Mesquita Filho" (UNESP), campus Rio Claro. Professora Titular na Universidade Federal de Juiz de Fora (UFJF), Juiz de Fora, Minas Gerais, Brasil. Endereço para correspondência: Campus Universitário, Rua José Lourenço Kelmer, São Pedro, Juiz de Fora, MG, Brasil, CEP: 36036-900. https://orcid.org/0000-0002-5123-9471. E-mail: sonia.clareto@ufjf.edu.br
\end{abstract}

Revista de Educação Matemática (REMat), São Paulo (SP), v.19, Edição Especial, pp. 1-20, e022009, 2022,

eISSN: 2526-9062

DOI: $10.37001 /$ remat25269062v19id726

Sociedade Brasileira de Educação Matemática Regional São Paulo (SBEM-SP) 
acontecimento. Com invenção de problemas, com e na processualidade, com e pelo meio, com aquilo que se apresenta e se instaura, currículo em experimentação.

Palavras-chave: Experimentação; Controle; Educação matemática.

\title{
A curriculum for training, what is it intended for?
}

\begin{abstract}
The article presents a writing in aphorisms problematizing the curriculum and training of teachers and, in composition, it drags mathematics education and education and school and classrooms and knowledge and mathematics and and... A curriculum for training is produced as an experiment and, with it, a teleological model is assumed as a goal to be achieved a certain experimentation. A curriculum for an education that carries canonical, hegemonic, universal modes, allied to Moral, Truth, Good and Beautiful, in the undertaking of the ideal and in the control of existence. In a safe harbor, the teacher bets on a curricular truth that has in the other a childish incapable, devoid of reason, then triggers their duty to lead him to good shape. A pedagogization of the curriculum. And, with all this, in experimentation: a curriculum in what happens, training as a process, involution. Twists with what is institutionalized, demarcated and postulated. And, in composition: curriculum and teacher training in what happens. Formative processes in experimentation resist models and goals affected by signs that present themselves with the forces that establish themselves and dispute in favor of other ways of existing and knowing. Certain experiments in what happens, curriculum in what happens: curriculum happening. With invention of problems, with and in the process, with and in the middle, with what is presented and established, curriculum in experimentation.
\end{abstract}

Keywords: Experimentation; Control; Mathematics education.

\section{Um currículo para una formación, ¿a qué está destinado? \\ RESUMEN}

El artículo presenta un escrito en aforismos que problematiza el currículo y la formación del profesorado y, en la composición, arrastra a la educación y a la educación matemática y a la escuela y a las aulas y al conocimiento y a las matemáticas y y y... Un currículo para una formación se produce como un experimento y, con él, se asume un modelo teleológico como una meta a la que alcanzar, entonces, cierta experimentación. Un currículo para una formación que lleva modos canónicos, hegemónicos, universales, aliados a la Moral, a la Verdad, al Bien y a la Belleza, en la empresa del ideal y el control de la existencia. Un docente en un puerto seguro apostando por una verdad curricular que tiene en el otro un incapaz infantilizado, desprovisto de razón, desencadena entonces su deber de conducirlo a la buena forma. Una pedagogización del currículo. Y, con todo ello, en la experimentación: un currículo en lo que sucede, una formación como proceso, la involución. Y, con lo que está institucionalizado, demarcado y postulado, torciones. Y, en la composición: currículo y la formación docente en lo que pasa. Procesos formativos en experimentación resisten a modelos y a objetivos afectados por los signos que se presentan con las

\author{
Revista de Educação Matemática (REMat), São Paulo (SP), v.19, Edição Especial, pp. 1-20, e022009, 2022, \\ eISSN: 2526-9062 \\ DOI: $10.37001 /$ remat25269062v19id726 \\ Sociedade Brasileira de Educação Matemática - Regional São Paulo (SBEM-SP)
}


fuerzas que se establecen y disputan a favor de otras formas de existir y conocer. Ciertas experimentaciones en lo que sucede, el currículo en lo que pasa: currículo acontecimiento. Con la invención de problemas, con y en la procesualidad, con y a través del medio, con lo que se presenta y establecido, el currículo en experimentación.

Palabras clave: Experimentación; Control; Educación matemática.

Currículo, em uma entrada pela etimologia: do latim curriculum, corrida, ato de correr, curso, percurso. Pedagogia, em uma entrada pela etimologia: do grego paidagogia, condução, direção, educação de crianças. Currículo: experimentação, meio, travessia; pedagogia: condução, controle, infantilização. Como uma pedagogia encontraum currículo?

Como uma pedagogia encontra um currículo? Uma operação se constitui: extrairda experimentação, dos meios, das travessias os modos para impor-se como idealidade. Como condução e controle, uma pedagogia neutraliza a radicalidade da experimentação, já que nela não há qualquer garantia dos meios e das travessias. Como condução e controle, uma pedagogia codifica as múltiplas entradas e saídas que constituem a experimentação, tomando certas experimentações como experimentações certas. Experimentações certas conduzem a meios certos e travessias certas. A formação, uma travessia certa, parte do pressuposto de um sujeito infantilizado, a ser conduzido e governado. Uma operação, uma pedagogização do currículo.

E ainda: que efeitos uma pedagogia constitui em um currículo? E ainda: que efeitos um currículo tem em uma pedagogia? E ainda: em nosso contemporâneo, como o atrito currículo-pedagogia produz efeitos na formação docente?

$* * * * *$

atrito

e

opor ao movimento. atritar sem movimento, estar estático. experimento. da saída à chegada, modelo do correr. 
e

atritar em movimento, estar dinâmico. um currículo corre, dinâmico. um currículo, um quem da energia cinética. quem, forças e quereres. um currículo atrita em um sóciopolítico-econômico-cultural. a força de atrito depende da força normal à superfície de contato e do coeficiente de atrito que compõem a superfície. força normal à superfície de contato elevada à enésima potência da experimentação, naquilo que pode a força. coeficiente de atrito, problematização, invenção de problemas. superfície, a pele, o mais profundo em experimentação.

e

o coeficiente de atrito estático nas matérias é sempre maior que o cinético. experimento tem mais lugar que experimentações? respostas, mais lugar que produção de problemas? representação tem mais lugar que o pensamento vampiro? significado: a força de atrito estático sempre será maior que a forma de atrito dinâmico. significado do significado: sempre será mais difícil começar um movimento do que manter o movimento. como? se o que há é processo, é entre, é meio, é experimentação? o que há é movimento. e...

$* * * * *$

sobre as mesas do grande salão: cartolina, papéis de vários tipos, tesouras, colas, revistas e a produção de um cartaz para responder à pergunta "como seria um mundo sem matemática?" (CLARETO; ROTONDO, 2014); se se tomar $17 x-17=x$ como verdadeiro, que álgebra acontece? (CAMMAROTA; ROTONDO; CLARETO, 2019); pedaços de barbante com medidas diferentes e quadradinhos de tamanhos diferentes e uma folha de papel A4 e produção de perímetros e áreas e e e... (ROTONDO, 2014); máquinas de subtrair postas a funcionar ou por empréstimo ou por compensação ou por um modo Adriana (ROTONDO; CAMMAROTA, 2020) e e e... e uma turma da licenciatura em matemática e uma turma da licenciatura em pedagogia e professoras e professores em uma reunião pedagógica numa escola pública; processos formativos em experimentação, 
currículo em acontecimento. Que matemática acontece? Que formação acontece?

$* * * * *$

condução

$\mathrm{e}$

avião. barco. barriga. braços. camelo. carta. carro. cavalo. charrete. celular. ciência. computador. consciência. currículo. disciplinas escolares. discurso. educação. estado. família. foguete. imagem. internet. jet-ski. jornal. leis. linguagem. mãe. mídia. moral. motocicleta. música. nave. navio. ônibus. oralidade. padre. pai. patins. pastor. pés. poder. prancha. processo formativo. professora. professor. religião. saber. skate. teoria. trem. tv. que, a seus modos, levam.

e

competências e habilidades. mobilizar conhecimentos, torná-los móveis, chamar a ação na produção de habilidades. mobilizar, então, experimentação com conhecimentos, com saberes. uma condução sem piloto, no âmbito da produção da habilidade, no existir: praticar, conhecer e viver, tornar-se hábil no existir enquanto um currículo acontece.

e...

$* * * * *$

o menino, no primeiro ano de ensino fundamental, fazia prova de avaliação de larga escala. Português e matemática. O menino, que aprendia as primeiras quantidades e as primeiras letras, fazia prova de avaliação em larga escala. Esperava, como as outras crianças, que alguém lesse o comando e as alternativas para só então responder. Uma vez Guattari (1985) escreveu que quanto mais cedo iniciamos as crianças aos sistemas semióticos dominantes, mais intensa é a operação de controle social. Controle, um programa de ação no regime das escolas: "as formas de controle contínuo, avaliação contínua, e a ação da formação permanente sobre a escola, o abandono correspondente de qualquer pesquisa na 
Universidade, a introdução da 'empresa' em todos os níveis de escolaridade.” (DELEUZE, 2013, p. 229). Quem fez essa prova, tia? Foi você? E a professora negou com a cabeça. Então foi a tia da coordenação? E a professora negou com a cabeça. Já sei! Foi o governo, não foi, tia? O governo é muito burro! O governo - ou ainda, o controle - é muito burro. A prova que nem é da professora, nem da coordenadora, nem da própria escola e que tudo tenta controlar, faz o menino ir dizendo coisas que nem nas alternativas da prova de matemática estavam. Ele mostra uma foto da moeda de vinte e cinco centavos e pergunta: de quanto é a moeda? O governo é muito burro! [composição com Giovani Cammarota (CAMMAROTA, 2021)].

controle

$\mathrm{e}$

quando aprender andar, poderá correr. quando aprender ouvir, aprenderá a falar. quando aprender a somar, aprenderá subtrair. quando aprender a multiplicar, aprenderá dividir. dada uma reta $\mathrm{r}$ e um ponto $\mathrm{P}$ fora dela, existe uma única reta que passa pelo ponto $\mathrm{P}$ e é paralela à reta dada. descontrole: geometrias não-euclidianas.

e

"A matemática, surgida na Antiguidade, por necessidade da vida cotidiana, converteu-se em um imenso sistema de variadas e extensas disciplinas. Como as demais ciências, reflete as leis sociais e serve de poderoso instrumento para o conhecimento do mundo e domínio da natureza” (BRASIL, 1997, p. 26).

$\mathrm{e}$

uma matemática surge em experimentação numa antiguidade, outra matemática surge noutra antiguidade, outra e outra e outra e e e... uma grega, uma maia, uma inca, uma oriental, uma ocidental, uma acidental, uma experimental, uma experimentada. uma matemática, em experimentação, surge. que é digno de entrar em um currículo? e... 
Infantilizar:

1. tomar, como no mito pedagógico dos gregos, a infância como algo a see controlado. “Também ali [nos textos de Platão] se afirma que a criança é a fera mais difícil de manejar porque, por sua potencial inteligência ainda não canalizada, é astuta, áspera e insolente." (KOHAN, 2003, p. 41-2). Instituir uma máquina binária criança-adulto que canalize a inteligência potencial em uma racionalidade educada.

2. aplicar a professoras e professores uma dupla operação: afirmar sua potencial inteligência como algo não canalizado; aplicar sobre a formação a necessidade de regulação por meio de conjuntos de diretrizes.

3. domar a escola, a formação, os currículos. Talvez por isso, Masschelein e Simons (2013, p. 105) afirmem que "Domar a escola implica governar seu caráter democrático, público e renovador". Eis aí a infância não como problema psicológico ou de desenvolvimento, mas em seu caráter político. Infantilizar implica, também, uma política para a infância.

4. infantilizar implica instaurar sobre a docência uma ordem explicadora, ou ainda, necessita de uma ordem explicadora, para utilizar uma expressão de Jacques Rancière. É que "É o explicador que tem necessidade do incapaz, e não o contrário, é ele que constitui o incapaz como tal. Explicar alguma coisa a alguém é, antes de mais nada, demonstrar-lhe que não pode compreendê-la por si só." (RANCIÈRE, 2017, p. 23).

5. Infantilizar, uma política de formação: constituir a ou o docente como incapaz, como infante, fazendo aparecer a necessidade de uma ordem explicadora capaz de domesticar, governar ou controlar aquilo que a escola tem de mais democrático: o provimento de tempo livre (MASSCHELEIN; SIMONS, 2013).

6. Infantilizar, uma política de formação: constituir a ou o docente como a pessoa civilizadora, como a detentora do saber gerenciado por um currículo, como a que assinala no outro - incapaz - um algo a mais, como a esclarecida e empreendedora que 'passa adiante' o que já havia sido pensado e descoberto e assumido como modelar (GADELHA COSTA, 2005, p. 1264).

Revista de Educação Matemática (REMat), São Paulo (SP), v.19, Edição Especial, pp. 1-20, e022009, 2022, eISSN: 2526-9062 
Ah, tem uma repetição, que sempre outras vezes em minha vida acontece. Eu atravesso as coisas - e no meio da travessia não vejo! — só estava era entretido na ideia dos lugares de saída e de chegada. Digo: o real não está na saída nem na chegada: ele se dispõe para a gente é no meio da travessia. Como é, então, que um se repinta e se sarrafa? Tudo sobrevém. Acho, acho, é do influimento comum, e do tempo de todos. Tanto um prazo de travessia marcada, sazão, como os meses de seca e os de chuva. Será? Digo ao senhor: naquele dia eu tardava, no meio de sozinha travessia. Mas eu não meditava para trás, não esbarrava. Aquilo era a tristonha travessia, pois então era preciso. Água de rio que arrasta. Dias que durasse, durasse; até meses. Será que tem um ponto certo, dele a gente não podendo mais voltar para trás? Travessia, ali, podia ser perigosa... travessia fácil... Não voltei? Travessias... Aquela travessia durou só um instantezinho enorme. Até os pássaros, consoante os lugares, vão sendo muito diferentes. Ou são os tempos, travessia da gente? Que: coragem - é o que o coração bate; se não, bate falso. Travessia - do sertão - a toda travessia. Travessia perigosa, mas é a da vida. Sertão que se alteia e se abaixa. Mas que as curvas dos campos estendem sempre para mais longe. Ali envelhece vento. E os brabos bichos, do fundo dele... Travessia. [composição com João Guimarães Rosa, com o grande sertão e suas veredas (GUIMARÃES ROSA, 1994)].

que se tome um exemplo tão simples como: $x$ se põe a ensinar matemática de novo... É um retorno controlado aos currículos, competências e habilidades? É uma maneira de morrer numa espécie de abolição completa do pensar? É uma nova borda, com uma linha ativa que vai provocar outros devires, devires inteiramente diferentes de tornar-se professor ou tornar a sê-lo, e que vai induzir uma transformação de todos os agenciamentos precedentes dos quais $x$ era prisioneiro? Uma saída? Um pacto com o diabo? A esquizoanálise ou a 
pragmática não tem outro sentido: faça rizoma, mas você não sabe com o que você pode fazer rizoma, que haste subterrânea irá fazer efetivamente rizoma ou fazer devir, fazer população no teu deserto. Experimente. [composição com Gilles Deleuz e Félix Guattari, em Mil Platôs, volume 4 (DELUEZE; GUATTARI, 1997, p. 29)].

\section{$* * * * *$}

experimentação: uma exterioridade que perturba; um fora que força o pensar; um não pensado no pensamento; implicação na heterogeneidade; ex do exterior, do fora; per do caminho, do currículo, da corrida, da travessia; ação no que acontece.

\section{finalidade}

$\mathrm{e}$

há? causas primeiras e efeitos últimos: há? se há, onde estão e quem os determina? quem? forças e quereres. um fim último para tudo que se conhece é mais uma crendice, melhor, ainda, uma necessidade de aplacar o medo e a insegurança... a impotência busca asilo no finalismo, e o fraco espera recompensas de deus por seu bom comportamento... quem forças e quereres - há de dizer que se trata de um erro ou de um acerto? um currículo para a formação inicial de professores e de professoras que ensinam matemática: um currículo que tem como finalidade a formação inicial de professores e de professoras que ensinam matemática? um currículo: a que será que se destina? o fim, a finalidade de formar? [...]. perder o rosto, ultrapassar ou furar o muro, limá-lo pacientemente, formar não tem outro fim [composição com Gilles Deleuze e Claire Parnet em Diálogos (DELEUZE; PARNET, 1998) e com Rafael Trindade em 5 Semelhanças entre Nietzsche e Espinosa, Razão Inadequada (TRINDADE, 2014)].

$\mathrm{e}$

"as áreas e componentes curriculares se articulam para promover a apropriação por 
crianças, jovens e adultos de diferentes linguagens, para reconhecer e interpretar fenômenos e processos naturais, sociais e culturais, para enfrentar problemas práticos, para argumentar e tomar decisões, individual e coletivamente". (BRASIL, 2017, p. 10) $\mathrm{e}$

articular promover reconhecer interpretar enfrentar argumentar tomar: ações; ações de um quem. quem: forças e quereres. “quem esse currículo 'pensa' que é e quem ele 'pensa' que são e podem vir a ser o estudante e outros protagonistas da educação escolar básica?" (CORREIA, 2018, p. 21).

e...

escrita de um encontro: uma menina com seus cinco anos mexia em uma caixa de blocos de madeira no horário de brincar na escola. Sentada debaixo do escorregador do parquinho, ela pegou dois discos de madeira: um bem fininho e outro mais grosso. Olhou para cima como quem matuta qualquer coisa e, aproveitando de um raro momento em que escorregador não estava ocupado, começou uma longa repetição: colocava o disco mais fino o mais alto que conseguia no escorregador para vê-lo rolar; e, depois, fazia o mesmo com o disco mais grosso; e, depois, colocava um ao lado do outro e os soltava juntos; e, depois, de tanto fazer, dizia a um colega que o mais fino ficava caindo e não rolava enquanto $o$ mais grosso não, o mais grosso sempre rolava; e depois ficava tentando fazer o mais fino não cair sem antes rolar pelo escorregador; e, depois, já com outros colegas, fazia os discos apostarem corrida de escorregador; e, depois, via quem conseguia fazer o disco mais fino rolar mais tempo sem cair; e e e... A menina ia se encontrando com os discos de madeira e, ao encontrá-los, ia encontrando algo com que não sabia lidar. Não tinha nome para dar, não tinha propriedades para reconhecer, um não pensado no pensamento, um quase nada... nada, a não ser uma longa e laborosa repetição de fazer os discos escorregarem. E de tanto fazer 
escorregar, um problema: um disco fino cai, será que dá para fazer com que ele não caia? E outro problema: que será que acontece quando os dois discos saem lado a lado e ao mesmo tempo? E outro problema: chamar os colegas para fazer daquela decifração uma corrida. E quantos mais? Quando a corrida virou brincadeira, importava pouco que a gente pudesse chamar os discos de madeira de cilindros ou que a gente pudesse dizer que cilindros são corpos redondos. Um impensado, um quase nada, ia fazendo violência na imagem de um acordo manso das faculdades no pensamento. Que fazer com isso? Insistir no escorregamento, coisa de criança, que decifrações constitui? Insistir no escorregamento, brincadeira de corrida, que decifrações constitui? Insistir em não nomear, não reconhecer, não representar, que decifrações constitui? Signo, um algo de mundo que nos força a pensar, que é objeto de um encontro fundamental, e não de uma recognição (DELEUZE, 2006).

e

escrita de uma codificação de um encontro fundamental: tendo em conta a escrita acima e tomando como referência a Base Nacional Comum Curricular, reconhecer na ação das crianças o Campo de Experiências "Espaços, Tempos, Quantidades, Relações e Transformações" os Objetivos de Aprendizagem e Desenvolvimento EI03ET01 Estabelecer relações de comparação entre objetos, observando suas propriedades - e EI03ET02 - Observar e descrever mudanças em diferentes materiais, resultantes de ações sobre eles, em experimentos envolvendo fenômenos naturais e artificiais (BRASIL, 2017). e

uma didática da codificação

O disco que girava no escorregador na hora da brincadeira na escola era a imagem de madeira rolante

Passou um professor e disse:

Essa figura que o disco faz...

se chama cilindro e é um corpo redondo

Não era mais a imagem de uma madeira rolante

No escorregador do parquinho da escola.

Era um cilindro.

Acho que o nome empobreceu a imagem.

Revista de Educação Matemática (REMat), São Paulo (SP), v.19, Edição Especial, pp. 1-20, e022009, 2022, eISSN: 2526-9062 
[composição com Manoel de Barros em Uma didática da invenção (BARROS, 2013)]. e...

um meio do meio do meio do meio do meio do meio do meio do meio do meio do meio do meio do meio do meio do meio do meio do meio do meio do meio do meio do meio do meio do meio do meio do meio do meio do meio do meio do meio do meio do meio do meio do meio do meio do meio do meio: experimentação, entre.

no meio do caminho tinha uma habilidade tinha uma competência no meio do caminho tinha uma habilidade no meio do caminho tinha uma competência.

Nunca me esquecerei que dentre eles, acontecimentona vida de minhas retinas tão fatigadas.

Nunca me esquecerei que no meio do caminho tinha um currículo tinha um currículo no meio do caminho no meio do caminho tinha era um currículo.

um meio do meio do meio do meio do meio do meio do meio do meio do meio do meio do meio do meio do meio do meio do meio do meio do meio do meio do meio do meio do meio do meio do meio do meio do meio do meio do meio do meio do meio do meio do meio do meio do meio do meio do meio: experimentação, entre.

[composição com Carlos Drummond de Andrade, em No meio do caminho (ANDRADE, 2013)].

$* * * * *$

Já fazia tempo que ela lecionava matemática para os pequenos. Sabia dividir há mais tempo

Revista de Educação Matemática (REMat), São Paulo (SP), v.19, Edição Especial, pp. 1-20, e022009, 2022, eISSN: 2526-9062 
ainda, pois alguém havia lhe ensinado quando pequena também. Na faculdade de p6edagogia, depurou esse conhecimento. Quis depurar um tanto mais num curso de formação continuada. Depurar mais um tanto a formação, para ficar mais precisa no que tinha a ensinar. E, num dos tantos encontros daquela formação continuada, vem, de novo, a divisão. E de novo vinha o dividendo, o divisor, o resto, o algoritmo. Experimento de reconhecer. Repetir repetir repetir, para ensinar melhor. E rasgando vinha: a divisão como distribuir ou mensurar, a grandeza como contínua ou discreta e o resto com seus tantos sentidos. Repetir repetir repetir, em experimentação. E ela, que a tanto ensinara a dividir, de tanto querer depurar para ser melhor, respira (ou pira?): Eu me sinto perdida diante detantos conceitos. Agora, vamos imaginar assim: quanto tempo eu já lido com a tal da Matemática? Ai, coitadas das minhas crianças!

De tanto depurar, pirou. De tanto experimentar, um fora, um risco, uma perturbação. Um currículo para uma formação? que currículo? que formação? [composição com Margareth Rotondo e Fernanda Azevedo (ROTONDO; AZEVEDO, 2017)].

$* * * * *$

formação

e

como invenção, sempre inicial, inaugural, disruptiva, criadora, autopoiética. Como processo, sempre continuada, pelo meio, atravessada.

e

em uma operação de controle absoluto, processo de subjetivação que decorre de uma determinada organização curricular que se impõe sobre cursos de licenciatura pela via das políticas de ingerência do Estado sobre a vida e, em nosso contemporâneo, uma introdução da empresa em todos os níveis de escolaridade, impondo os valores da eficácia - atingir metas, sejam elas uma determinada competência ou habilidade disposta de uma organização curricular ou um índice de rendimento e referência utilizado para balizar as políticas públicas educacionais - da eficiência - atingir as metas de modo mais rápido e com o menor

Revista de Educação Matemática (REMat), São Paulo (SP), v.19, Edição Especial, pp. 1-20, e022009, 2022, eISSN: 2526-9062 
custo possível, incorporando a privatização da escola e dos saberes ainda que se trate do funcionamento da escola pública - e do desempenho - tendo nas organizações curriculares baseadas nas competências e habilidades a linha de julgamentoque faz fiar os valores aos sujeitos. Formação e currículo, uma relação causal: o currículo vem primeiro, organiza e sedimenta o caminho para que a formação venha depois, afeita à máquina social capitalista. Uma pedagogia conduz a formação, fazendo currículo.

e

por um lado, formação: sempre inicial no sentido de que sempre inaugura alguma coisa; por outro, inauguração: sempre um entre, acontece pelo meio. Currículo: experimentação, meio, travessia. Seria a formação um efeito do currículo ou o currículo o efeito de uma formação? Currículo, um acontecimento: tantas outras políticas, tantas outras relações, uma dessubjetivação, uma desterritorialização da máquina social e suas organizações, dispositivos e controles.

$\mathrm{e}$

processo produção processo produção processo produção processo produção processo involução involução involução involução involução involução involução in... uma das tantas facetas da formação. que currículo? que travessia? experimentação no que acontece.

e

um currículo para uma formação verdadeira, um conhecimento verdadeiro a ser bem ensinado por um bom professor e uma boa professora. recursos e metodologias para o um ensinar ideal. uma das facetas da formação: ideal messiânico do bom professor e da boa professora, do bem e da verdade. que currículo? que travessia?

e

"enquanto processo de dessubjetivação; produção na relação com o que acontece. Maquinaria na dissolução de identidades. Formação que desforma a forma; que disforma a fôrma; que nega a docência em seu caráter universal, protótipo de um ideal. [..] Formação que abandona a potência negativa para se converter em pura afirmação.” (BELCAVELLO, 2021, p. 40).

e... 
uma política de formação inicial de professoras e de professores - relação público-privado, projeto de privatização do ensino, concepção restrita de competências, "Direito à aprendizagem" versus "Direito à Educação" formação para trabalhadoras produtivas e para trabalhadores produtivos, servis, sintonizados com as necessidades do mercado - é imposta. Uma formação técnico-instrumental e meritocrática é imposta. Um conjunto de normativos legais - como as Diretrizes Curriculares Nacionais para a formação de professores (Resolução CNE/CP 01/2019), as Diretrizes Curriculares Nacionais para a Formação Continuada de Professores da Educação Básica (Resolução CNE/CP nº 1, de 27/10/2020) e BaseNacional Comum para a Formação Continuada de Professores da Educação Básica (BNC-Formação Continuada) - é imposto. Uma política uníssona - total alinhamento da formação inicial à BNCC e à BNC-Formação - é imposta. Palavras-chave: meritocracia, imposição, subordinação, desqualificação, prescrição, degradação, desvalorização. Política de formação docente, a que será que se destina?

$* * * * *$

numa aula de matemática entra: fome, desemprego, mortes por COVID, pandemia, mortes de crianças negras e pobres por "balas perdidas", racismo, homofobia, transfobia, xenofobia, gravidez na adolescência, violência infantil, violência contra a mulher e e e... e não se trata de uma aula de estatística com tabelas e gráficos.

$* * * * *$

para: há um dedo para um anel. há um corpo para uma blusa. há um doce para uma criança. há um início para um fim. há um dia para uma noite. há uma cor para uma bandeira. há um ensino para um aprender. há um futuro para um presente. há um modelo para um projeto. há um currículo para uma formação. há um discurso para uma consciência. há uma moral 
para uma lei. que há quando há para? há uma corrida para um fim. teleologia.

$$
* * * * *
$$

uma escola e um currículo e uma formação:

que podem?

que conhecer com um currículo?que existir com um currículo? que formação com um currículo?

um currículo experimento aciona o modelo, a meta, o fim. conhecimento enquanto representação, acesso ao já dado, ao já pensado, ao já imaginado. porto seguro.

processo cognitivo e processo vital se recobrem mutuamente.

um currículo em experimentação no que acontece abre-se à perturbação do pensar, à desativação da forma, à invenção das travessias, à produção dos modos, ao ainda não pensado, ao imemorial, ao afásico, ao agnóstico. perdição, risco.

processo cognitivo e processo vital se recobrem mutuamente.

que existir se produz com um currículo numa escola? que currículo para um existir? [composição com Tiago Adão Lara (LARA, 2016)].

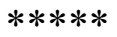

percurso: a caminho de casa, um per. a caminho de um ethos, exercício. em exercício, experiência. em experiência, perturbação. a caminha de casa, um curso. num curso, percalços. em percalços, experimentação. processo. num ethos, só processo. involução. nunca inicial, nem final, só processo.

$* * * * *$

Currículo como experimentação, meio, travessia. Como experimentação, um currículo afirma um encontro com o signo que força a pensar, força a forjar os modos de 
decifração e com eles, uma travessia, uma aprendizagem, uma formação. Como meio, um currículo afirma-se como um disruptivo: não apela a uma gênese que garante um início ou a uma teleologia que vai garantir os fins. Como travessia, um currículo afirma uma batalha entre subjetivação e dessubjetivação, entre os modos canônicos, sacralizados de pensar e fazer e a instauração dos problemas que os signos fazem germinar. Se "Nunca se sabe de antemão como alguém vai aprender - que amores tornam alguém bom em latim, por meio de que encontros se é filósofo em que dicionários se aprende a pensar." (DELEUZE, 2006, p. 237), nunca se sabe de antemão que currículo vai acontecer, que amores tornam alguém bom em matemática, por meio de que encontros se é professora e professor, por meio de que dicionários se aprende a pensar. Um currículo, um acontecimento, afirma-se como efeito, reconfiguração de potências (LAPOUJADE, 2015).

\section{REFERÊNCIAS}

ANDRADE, C. D. de. Alguma poesia. São Paulo: Companhia das Letras,2013.

BARROS, M. de. Poesia Completa. São Paulo: Editora Leya, 2013.

BELCAVELLO, M. P. P. S. Facetas do cristal das docências: potência do falso, fio da entreter uma formação em tes(c)e. 2021. Texto $2^{\circ}$ Exame de Qualificaçãode Doutorado (Doutorado em Educação) - Faculdade de Educação, Universidade Federal de Juiz de Fora, Juiz de Fora, 2021.

BRASIL. Ministério da Educação. Parâmetros Curriculares Nacionais Matemática anos iniciais. Vol. 3. Brasília, 1997. Disponível em:

http://portal.mec.gov.br/seb/arquivos/pdf/livro03.pdf. Acesso em: 25 jul. 2021.

BRASIL. Ministério da Educação. Base Nacional Comum Curricular. Brasília, 2017. Disponível em:

http://basenacionalcomum.mec.gov.br/images/BNCC_EI_EF_110518_versaofinal_site. pdf. Acesso em: 25 jul. 2021.

BRASIL. Ministério da Educação. Resolução CNE/CP n. ${ }^{0}$ 2, de 20/12/2019. Define as Diretrizes Curriculares Nacionais para a Formação Inicial de Professores para a Educação Básica einstitui a Base Nacional Comum para a Formação Inicial de Professores da Educação Básica (BNC-Formação). Brasília, 2019. Disponível em: http://portal.mec.gov.br/index.php?option=com_docman\&view $=$ download\&alias $=1359$ 
51-rcp002-19\&Itemid=30192. Acesso em: 25 jul. 2021.

BRASIL. Ministério da Educação. Resolução CNE/CP n.o 1, de 2/07/2019. Altera o Art. 22 da Resolução CNE/CP n. ${ }^{\circ}$ 2, de 1 de julho de 2015, que define as Diretrizes Curriculares Nacionais para a formação inicial em nível superior (cursos de licenciatura, cursos de formação pedagógica para graduados e cursos de segunda licenciatura) e para a formação continuada. Brasília, 2019. Disponível em:

http://portal.mec.gov.br/index.php?option $=$ com docman\&view $=$ download\&alias $=1167$ 31-rcp001-19\&category_slug=julho-2019-pdf\&Itemid=30192. Acesso em: 25 jul. 2021.

BRASIL. Ministério da Educação. Resolução CNE/CP n. ${ }^{\circ}$ 1, de 27/10/2020. Dispõe sobre as Diretrizes Curriculares Nacionais para a Formação Continuada de Professores da Educação Básica e institui a Base Nacional Comum para a Formação Continuada de Professores da Educação Básica (BNC-Formação Continuada). Brasília, 2020. Disponível em: http://portal.mec.gov.br/docman/outubro-2020-pdf/164841-rcp001-20/file. Acesso em: 25 jul. 2021.

CAMMAROTA, G. Fascículos de experiências: rastros de um estudo com crianças e matemáticas, inventividade e cultura ou Pesquisar em modo João. 2021. 176

f. Tese (Doutorado) - Curso de Doutorado em Educação, Universidade Estadual Paulista "Júlio de Mesquita Filho"- Campus Rio Claro, Rio Claro, 2021. Disponível em: https://repositorio.unesp.br/handle/11449/215222 Acesso em: 25 jul. 2021.

CAMMAROTA, G.; ROTONDO, M. A. S.; CLARETO, S.M. Formação docente: exercício ético estético político com matemáticas.

Perspectivas da Educação Matemática, v. 12, n. 30, p.679-694, dez.2019. Disponível em: https://periodicos.ufms.br/index.php/pedmat/article/view/9605. Acesso em: 25 jul. 2021.

ClARETO, S. M.; ROTONDO, M. A. S.. Como Seria um Mundo sem Matemática? Hein?! Na tensão narrativa-verdade. Bolema: Boletim deEducação Matemática, v. 28, n. 49, p.974-989, ago. 2014. Disponível: http://dx.doi.org/10.1590/1980-4415v28n49a26. Acesso em: 25 jul. 2021.

CLARETO, S. M.; ROTONDO, M. S. O que torna uma matemática digna de ocupar lugar em um currículo de licenciatura em matemática?.Perspectivas da Educação

Matemática, v. 14, n. 35, 2021. Disponível em: https://periodicos.ufms.br/index.php/pedmat/article/view/13412/9357. Acesso em: 25 jul. 2021.

CORREIA, W. F. Ensino de filosofia e o endereçamento de ética nos PCN: controle ou democracia? 2008. 211 f. Tese (Doutorado) - Curso de Doutoradoem Educação, Universidade Estadual de Campinas, Campinas, 2008. Disponível em: 
https://1library.org/document/z3een39q-ensino-filosofia-problema-enderecamentocurricular-etica-controle-democracia.html. Acesso em: 25 jul. 2021.

DELEUZE, G.; PARNET, C. Diálogos. São Paulo: Escuta, 1998.

DELEUZE, G. Diferença e Repetição. Rio de Janeiro: Graal, 2006.

DELEUZE, G. Post-scriptum sobre as sociedades de controle. In: DELEUZE,Gilles. Conversações: 1972-1990. São Paulo: Editora 34, 2013. p. 219-226.

DELEUZE, G.; GUATTARI, F. Mil Platôs: capitalismo e esquizofrenia 2, volume 4. São Paulo: Editora 34, 1997.

GADELHA COSTA, S. de S. De fardos que podem acompanhar a atividade docente ou de como o mestre pode devir burro (ou camelo). Educação e Sociedade, v. 26, n. 93, p. 1257 - 1272, set./dez. 2005. Disponível em:

https://www.scielo.br/j/es/a/9sTsg3w8DPJmnnTNRhKGwJj/abstract/?lang=pt\&format= html. Acesso em 25 jul. 2021.

GUIMARÃES ROSA, J. Grande sertão: veredas. Rio de Janeiro: Editora NovaAguilar, 1994.

KOHAN, W. Infância: entre educação e filosofia. Belo Horizonte: Autêntica, 2003.

LARA, T. A. Educação: conflitos, tarefa, desafio, perguntação, ética,subjetivação, cultura, aprendizagem, alegria. Juiz de Fora: Gryphon, 2016.

LAPOUJADE, D. Deleuze, os movimentos aberrantes. São Paulo: n-1 Edições,2015.

MASSCHELEIN, J.; SIMONS, M. Em defesa da escola: uma questão pública.Belo Horizonte: Autêntica, 2013.

RANCIÈRE, J. O mestre ignorante: cinco lições sobre a emancipaçãointelectual. Belo Horizonte: Autêntica, 2017.

ROTONDO, M. A. S. Fazer da matemática problema a ser inventadoinventando formação. Educação \& Realidade, v. 39, n. 4, p. 1071-1087, 2014. Disponível em: https://seer.ufrgs.br/educacaoerealidade/article/view/45896. Acesso em: 25 jul. 2021.

ROTONDO, M. A. S.; CAMMAROTA, G. Formar, um acontecimento: subtrair variando em modos esquilo. In: MIGUEL, Antônio; VIANNA,Carlos Roberto; CORRÊA, Júlio Faria (orgs.). Uma historiografia terapêutica de acasos. Uberlândia: Navegando Publicações, 2020. p. 437-450. Disponível em: https://www.editoranavegando.com/livrouma-historiografia-terapeutic. Acesso em 25 jul. 2021.

Revista de Educação Matemática (REMat), São Paulo (SP), v.19, Edição Especial, pp. 1-20, e022009, 2022, eISSN: 2526-9062 
ROTONDO, M. S.; AZEVEDO, F. de O. A tal da matemática: um problema?. Revemat: Revista Eletrônica de Educação Matemática,[S.L.], v. 11, p. 308, 25 jan. 2017. Universidade Federal de Santa Catarina (UFSC). Disponível em: http://dx.doi.org/10.5007/1981-1322.2016v11nespp308. Acesso em: 25 jul. 2021.

TRINDADE, R. Cinco semelhanças entre Nietzsche e Espinosa. 2014. Disponível em: https://razaoinadequada.com/2014/01/26/5-semelhancas-entre-nietzsche-e-espinosa/. Acesso em: 01 ago. 2021. 